\title{
Farklı Sıcaklıkların SIFCON Betonunun Mekanik özeliklerine Etkisinin Íncelenmesi
}

Ferhat Aydın

Sakarya Uygulamalı Bilimler Üniversitesi, Teknoloji Fakültesi, İnşaat Mühendisliği Bölümü, Sakarya, Türkiye

\begin{abstract}
Özet
Çimento, silis dumanı, kuvars kumu ile birlikte çok miktarda çelik liflerin bulunduğu, yüksek eğilme dayanımı, süneklik ve tokluk özeliklerine sahip SIFCON betonlar yeni nesil yapı malzemelerindendir. SIFCON bu özeliklerinden dolayı askeri yapılar ve sığınaklar gibi yüksek enerji yutma kapasitesine sahip yapılarda kullanılmasından dolayı yangın ve patlama gibi sebeplerden dolayı yüksek sıcaklığa maruz kalabilmektedirler. Bu çalışmada SIFCON betonların yüksek ve düşük ısılarda basınç ve eğilme davranışları incelenmiştir. Hacimce çelik lif oranı \%24 olan 10 adet küp (100x100x100 mm) ve 10 adet kiriş $(74 \times 74 \times 500 \mathrm{~mm})$ SIFCON numuneleri üretilmiştir. Gerekli kür işlemleri yapıldıktan sonra -35 , $+22,+100,+200,+300{ }^{\circ} \mathrm{C}$ derecelerdeki ısıların etkisinde eğilme ve basınç davranışları belirlenmiştir. Kiriş numunelerin yük-sehim grafikleri çizilerek eğilme dayanımı, kırılma tokluğu değerleri belirlenmiş ve küp numunelerinin ise basınç dayanımları karşılaştırılmıştır.
\end{abstract}

Anahtar Kelimeler: SIFCON, Isı, basınç dayanımı, eğilme dayanımı, tokluk

\section{Investigation of the Effect of Different Temperatures on Mechanical Properties of SIFCON}

\begin{abstract}
SIFCON is one of the new generation building materials which has high bending strength, ductility and toughness properties including cement, silica fume, quartz sand and large amount of steel fibers. Because of these properties, SIFCON concrete can be exposed to high temperatures due to fire and explosion because it is used in military structures and shelters. In this study, compressive and flexural behavior of SIFCON at high and low temperatures were investigated. SIFCON samples of 10 cube (100x100x100 $\mathrm{mm})$ and 10 beams $(74 \times 74 \times 500 \mathrm{~mm})$ were produced with $24 \%$ by volume steel fiber ratio. After curing procedures, compressive and flexural behaviour were determined under the influence of temperatures of $-35,+22,+100,+200,+300{ }^{\circ} \mathrm{C}$. Flexural strength and fracture toughness values of the beam samples were determined by drawing the load-deflection graphs and the compressive strengths of the cube samples were compared.
\end{abstract}

Key words: SIFCON, temperature, compressive strength, flexural strength, toughness

\section{Giriş}

Günümüzde dünyada en çok kullanılan yapı malzemesi olan betonun en büyük eksiği olarak gevrekliği gösterilmektedir. Araştırmacılar betonu daha sünek davranması için sürekli çalışmalar yapmaktadır. Betonun kırılması sırasında sönümlenen enerji miktarının düşük olması, gevrek kırılmayı önlemek ve sünek davranış elde etmek için beton içerisine çeşitli lifler eklenmektedir.

*Corresponding author: Address: Department of Civil Engineering, Faculty of Technology, Sakarya University of Applied Sciences, 54187, Sakarya TURKEY. E-mail address: ferhata@ subu.edu.tr, Phone: +902646160240 
Genellikle betona kısa çelik lifler ilave edilerek çözümler üretilmektedir. Son yıllarda geliştirilen kalıp içerisine yoğun miktarda çelik liflerin \%5-20 oranında yerleştirilmesinin ardından çimento, su, akışkanlaştırıcı katkı, silis dumanı ve kuvars kumundan oluşan bulamacın çelik liflerin içerisine dökülmesi sonucunda SIFCON olarak isimlendirilen yüksek çekme dayanımı, enerji yutma kapasitesi ve basınç dayanımına sahip çimento esaslı betonlar geliştirilmiştir. Klasik çelik lifli betona göre yaklaşık 10 kata varan oranda çelik liflerin kullanılması SIFCON'ların daha sünek olmasını sağlamakla birlikte daha yüksek dayanımlara ulaşılmaktadır. Yüksek tokluk ve düktilite sayesinde yapı güçlendirmesinde, endüstriyel zeminlerde, askeri yapılarda kullanılabilmektedir. Savunma amaçlı askeri amaçlarla kullanılabilen SIFCON betonlar yangın ve patlama kaynaklı etkilerden dolayı yüksek sicaklıklara maruz kalabilmektedirler.

Yüksek sıcaklıkların SIFCON'a etkisinde $100 \mathrm{C}^{0}$ 'de kılcal boşluklardaki su uzaklaşmakta, jeldeki adsorbe su ve hidratlardaki bünye suyu $300 \mathrm{C}^{\circ}$ 'ye doğru buharlaşmaya başlamaktadır. Bu aşamada betonda büzülme önemli seviyelerde ve yapıdan dışarı çıkmaya çalışan su, boşluklarda buhar basıncı oluşturmaktadır. $300 \mathrm{C}^{\mathrm{o}}$ den itibaren alüminli ve demiroksitli bileşenler dehidrate olmaya başlamakta, $400 \mathrm{C}^{\mathrm{o}}$ dolaylarında $\mathrm{Ca}(\mathrm{OH})_{2}$ 'den $\mathrm{CaO}$ 'e dönüşüm başlamakta ve $600 \mathrm{C}^{\circ}$ 'ye yaklaştıkça C-S-H yapısı hızla tahrip olmaktadır [1]. Yüksek sıcaklık etkisinde numune nem içeriğindeki artış buhar basıncını artırmaktadır. Silis dumanı kullanımı sonucu boşluk sistemindeki azalma ve çaplardaki daralma sebebiyle özellikle yüksek dayanımlı betonlar patlayarak parçalanabilmektedir. Aydın ve arkadaşlarının [2] çalışmasında yüksek dayanımlı lifsiz harçlarda parçalanma $300 \mathrm{C}^{0}$ 'nin üstünde oluşmuştur. Çelik lifli numunelerde ise $300 \mathrm{C}^{\circ}$ 'de eğilme dayanımı artışı belirtilmiştir. $300 \mathrm{C}^{\mathrm{o}}$ sıcaklık sonrasında dayanımların artışının sebebi, C-S-H yapısı henüz bozulmamış matrisin kuruma büzülmesi ile lif çeperini sıkıştırması olabileceği ifade edilmiştir. Ayrıca $600 \mathrm{C}^{\circ}$ 'ye maruz kalan SIFCON numunelerinde yapılan gözlemsel incelemede özellikle yüzeydeki liflerin karardığı ve kırılganlığının arttığı tespit edilmiş̧tir. Bu sebeple, yüksek sıcaklığa karşı SIFCON yapı elemanlarının tüm yüzeylerin pas payı benzeri koruyucu bir harç tabakası ile kaplanması önerilmekte ve böyle bir yöntem korozyonun önlenmesinde etkindir.

Shannag ve arkadaşları [3] tarafından yapılan bir çalışmada SIFCON içerisinde süreksiz bir şekilde dağılı olarak bulunan çelik tellerin betonda çatlak oluşumunu önemli ölçüde azalttığı, betonun şekil değiştirme kapasitesini, tokluğunu, çarpma ve çekme dayanımını arttırdığı ve süneklik düzeyi yüksek betonlar elde etmeyi mümkün kıldığı görülmüştür. Bayramov ve arkadaşları [4] tarafından istatistiksel tepki yüzey modellemesi kullanarak yapılan bir çalışmada çelik tellerin yüksek performanslı betonlar üzerindeki etkileri incelenmiş̧; çelik tel içeriğinin ve narinliğinin artmasıyla kırılana kadar yutulan enerjinin arttığı ve malzemenin daha sünek davranış sergilediği sonucuna varılmıştır. Naaman [5] SIFCON'da silis dumanı ve çelik lif etkisini beraber incelemiştir. Bu ikilinin darbe etkisi altında ve yorulma sırasında oluşan hasarları farklı şekillerde olsa da birbirlerini tamamlayıcı şekilde engellediklerini belirtmişdir.

Araştırmacılar tarafından SIFCON beton kullanarak betonarme kirişlerin kayma etkisine karş1 onarımı ve güçlendirilmesi [6], atık lastiklerinden elde edilen çelik lifler kullanılarak üretilen SIFCON betonun performansının değerlendirilmesi [7] ve SIFCON levhaların darbe etkisindeki davranış1 [8] deneysel olarak araştırılmıştır. Reaktif pudra betonu ve SIFCON betonun birlikte kompozit olarak tasarlanması ve sıkıştırma basıncı uygulanması [9], silindir beton numunelerin GFRP kumaşla sarılması ile SIFCON ile güçlendirilmesinin karşılaştırılması [10], SIFCON 
matrisindeki tek çelik lifin çekme davranışının belirlendiği [11] ve üç eksenli basınç altında SIFCON betonun davranışı [12] konularında yapılmış çalışmalar mevcuttur. Sicaklık etkisinde SIFCON betonun eğilme davranışı incelendiği çalışmada [13] standart veya buharla kür edilmiş SIFCON beton numuneleri 300, 600, 750 ve $900 \mathrm{C}^{\circ \prime}$ ye tabi tutulmuştur. Numunelerin $300 \mathrm{C}^{\circ} \mathrm{ye}$ maruz bırakılması mekanik performansı arttırırken, daha yüksek sıcaklıklarda çelik liflerin kesitindeki kayıp ve C-S-H jel yapısının tahrip olması gibi nedenlerle olumsuz etkiler tespit edildiği belirtilmiştir.

Bu çalışma kapsamında; SIFCON beton kiriş ve küp numuneler üretilerek $-35,+22,+100,+200$, $+300 \mathrm{C}^{0}$ arasındaki ısılarda eğilme ve eksenel basınç deneyleri gerçekleştirilmiştir. Yapılan testler sonucunda eğilme dayanımları, basınç dayanımları, yük-sehim grafikleri ve tokluk değerleri değerlendirilmiş ve SIFCON betonun sıcaklık etkisindeki davranışları incelenmiştir.

\section{Malzeme ve Metot}

Deneysel çalışmalarda 74x74x500 mm boyutlarında 10 adet kiriş numunesi ve 100x100x100 mm boyutlarında 10 küp numune olmak üzere 2 grup toplam 20 adet SIFCON beton üretilmiştir. PÇ 42,5 CEM I R tipi çimento, silis dumanı, kuvars kumu kullanılmıştır. Çelik lifler iki ucu kıvrılmış, soğuk çekilmiş, $50 \mathrm{~mm}$ boyunda, $1 \mathrm{~mm}$ çapında ve $7,80 \mathrm{gr} / \mathrm{cm}^{3}$ özgül ağırlı̆̆a sahiptir. Kimyasal katkı olarak süper akışkanlaştırıcı Polycar 300 kullanılmıştır. Bulamacın su/çimento oranı 0,30 ve lif miktarı hacimce \%24 olarak belirlenmiştir. Silis dumanı çimento ağırlığının \%20'si ve katkı/çimento oranı 0,01'dir. Beton karışım oranları Tablo 1'de verilmiştir.

Tablo 1. Beton karışım oranları

\begin{tabular}{cc}
\hline & Malzeme Miktarı (kg) \\
\hline Çimento & 1045 \\
\hline Su & 314 \\
\hline Silis & 209 \\
\hline Kuvars & 335 \\
\hline Katkı & 10,45 \\
\hline Toplam & 1913,45 \\
\hline
\end{tabular}

Beton bulamaç hazırlanıp çelik lif yerleştirilmiş kalıplara dökülerek, vibrasyon uygulanarak üretilmiştir (Şekil 1). Prizi gerçekleşen numunelere 3 gün boyunca $90 \mathrm{C}^{\circ}$ de buhar kürü uygulanmış, daha sonra buhar kür havuzuna konularak toplam 28 günlük kür edilmiştir. 


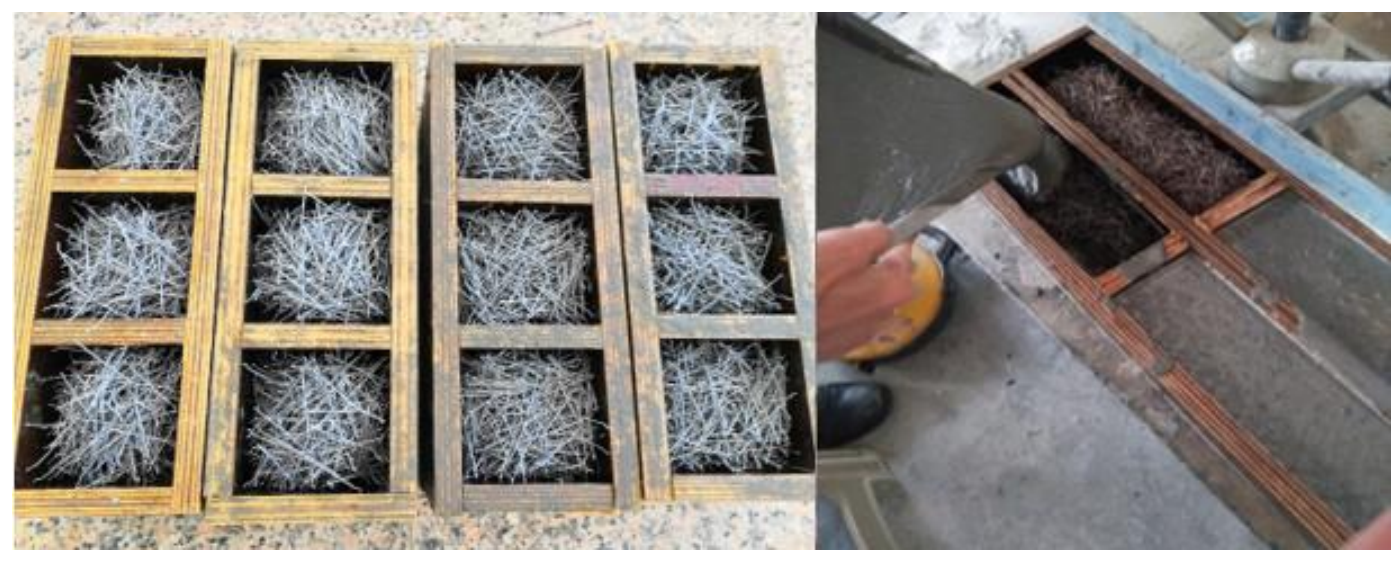

Şekil 1. Çelik liflerin kalıba yerleştirilmesi ve bulamacın kalıplara dökülmesi

Yeterli dayanıma ulaşan küp ve kiriş numuneler istenilen ısılara ulaşması için düşük 1sılarda derin dondurucuda, yüksek ısılarda firında bekletilmiştir. Düşük ısılarda - $30 \mathrm{C}^{0}$, oda sıcaklığında $+22 \mathrm{C}^{0}$ ve yüksek 1sılarda ise $+100 \mathrm{C}^{0},+200 \mathrm{C}^{0},+300 \mathrm{C}^{0}$ 'de basınç ve eğilme testleri gerçekleştirilmiştir. Şekil 2' de küp ve kiriş numunelerin 1sıtılması ve testleri görülmektedir.

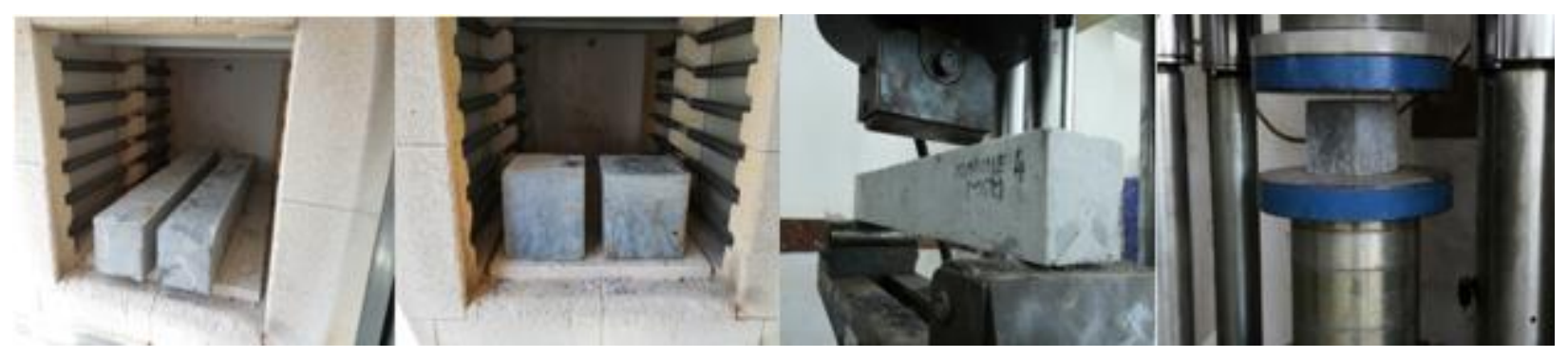

Şekil 2. Numunelerin firında ısıtılması ile eğilme ve basınç deneyleri

\section{Eğilme Deneyi Sonuçları}

Üç noktalı eğilme deneyleri soncusunda hesaplanan eğilme dayanımı ve tokluk değerleri Tablo 2 'de, elde edilen verilere göre her 1sı değeri için iki kiriş numunenin çizilen yük-sehim grafikleri Şekil 3-7'de verilmiştir.

Tablo 2. Eğilme dayanımı ve kırılma tokluk değerleri 


\begin{tabular}{|c|c|c|c|c|c|c|c|c|}
\hline \multirow{3}{*}{$\begin{array}{c}\begin{array}{c}\text { Sicaklık } \\
\left(C^{0}\right)\end{array} \\
-30\end{array}$} & \multicolumn{4}{|c|}{ Ĕgilme Dayanımı (N/mm²) } & \multicolumn{4}{|c|}{ Tokluk (kNmm) } \\
\hline & 1 & 22.27 & Ortalama & 26,89 & 1 & 140.5 & Ortalama & 161,6 \\
\hline & 2 & 31.52 & & & 2 & 182.8 & & \\
\hline \multirow[t]{2}{*}{+22} & 1 & 19.61 & \multirow[t]{2}{*}{ Ortalama } & \multirow[t]{2}{*}{20,55} & 1 & 112.3 & \multirow[t]{2}{*}{ Ortalama } & \multirow[t]{2}{*}{106,3} \\
\hline & 2 & 21.49 & & & 2 & 100.2 & & \\
\hline \multirow[t]{2}{*}{+100} & 1 & 17.32 & \multirow[t]{2}{*}{ Ortalama } & \multirow[t]{2}{*}{19,16} & 1 & 87.6 & \multirow[t]{2}{*}{ Ortalama } & \multirow[t]{2}{*}{92,0} \\
\hline & 2 & 20.99 & & & 2 & 96.4 & & \\
\hline \multirow[t]{2}{*}{+200} & 1 & 12,76 & \multirow[t]{2}{*}{ Ortalama } & \multirow[t]{2}{*}{12.88} & 1 & 69,8 & \multirow[t]{2}{*}{ Ortalama } & \multirow[t]{2}{*}{$\mathbf{7 3 , 1}$} \\
\hline & 2 & 13,01 & & & 2 & 76,4 & & \\
\hline \multirow{2}{*}{+300} & 1 & 11.83 & \multirow{2}{*}{ Ortalama } & \multirow{2}{*}{14,02} & 1 & 104,6 & \multirow{2}{*}{ Ortalama } & \multirow{2}{*}{111,5} \\
\hline & 2 & 16,21 & & & 2 & 118,7 & & \\
\hline
\end{tabular}

En yüksek eğilme dayanımına $-30 \mathrm{C}^{\mathrm{o}}$ ' de $26,89 \mathrm{~N} / \mathrm{mm}^{2}$, en düşük eğilme dayanımına $+200 \mathrm{C}^{\circ}$ ' de $12,88 \mathrm{~N} / \mathrm{mm}^{2}$ değeri ile ulaşılmıştır. SIFCON betonun oda sıcaklı̆̆ındaki eğilme dayanımı 20,55 $\mathrm{N} / \mathrm{mm}^{2}$ bulunmuştur. Genellikle sıcaklık arttıkça eğilme dayanımımn azaldığı belirlenmiştir. Oda sıcaklığı referans alındığında $-30 \mathrm{C}^{\mathrm{o}}$ 'de düşük sıcaklıkta yaklaşık eğilme dayanımının $\% 30$ oranında arttı̆̆ tespit edilmiştir. Yüksek sıcaklıklarda +200 ve $+300 \mathrm{C}^{\circ}$ de sirasıyla $\% 37$ ve $\% 31$ oranında dayanımın düştüğü belirlenmiş̧ir. Tokluk sonuçları incelendiğinde eğilme dayanımında olduğu gibi en yüksek tokluk değeri $-30 \mathrm{C}^{\circ}$ ' de $161,6 \mathrm{kNmm}$, en düşük $+200 \mathrm{C}^{0}$ ' de $73,1 \mathrm{kNmm}$ bulunmuştur. Oda sıcaklığında tokluk 106,3 kNmm olmak üzere $-30 \mathrm{C}^{\circ}$ 'de tokluk değeri $\% 52$ oranında arttığ $1,+300 \mathrm{C}^{0}$ 'de sünekleşerek yaklaşık $\% 5$ oranında artış belirlenmiştir. +100 ve $+200 \mathrm{C}^{\circ}$ 'de sirasıyla tokluğun $\% 13$ ve $\% 31$ oranında düştügü tespit edilmiştir.

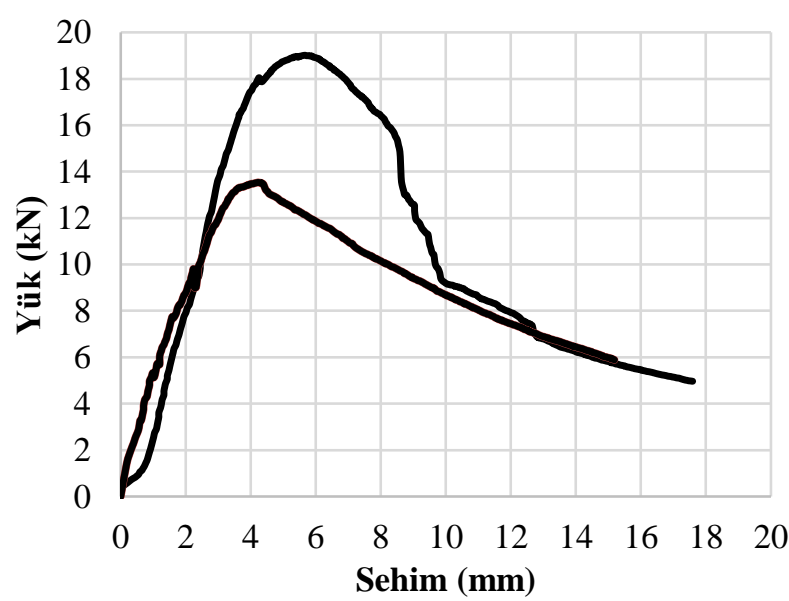

Şekil 3. Yük-sehim grafikleri $\left(-30 \mathrm{C}^{0}\right)$

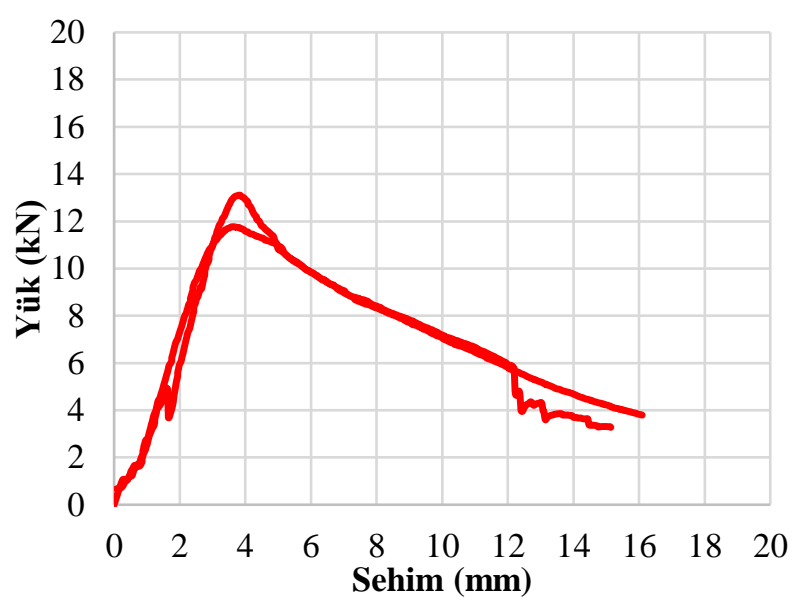

Şekil 4. Yük-sehim grafikleri $\left(+22 \mathrm{C}^{0}\right)$ 


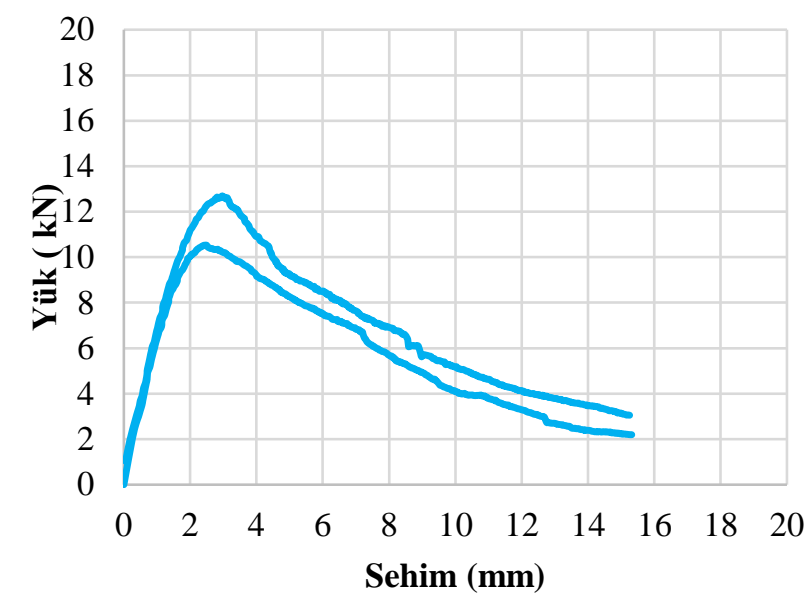

Şekil 5. Yük-sehim grafikleri $\left(+100 \mathrm{C}^{0}\right)$

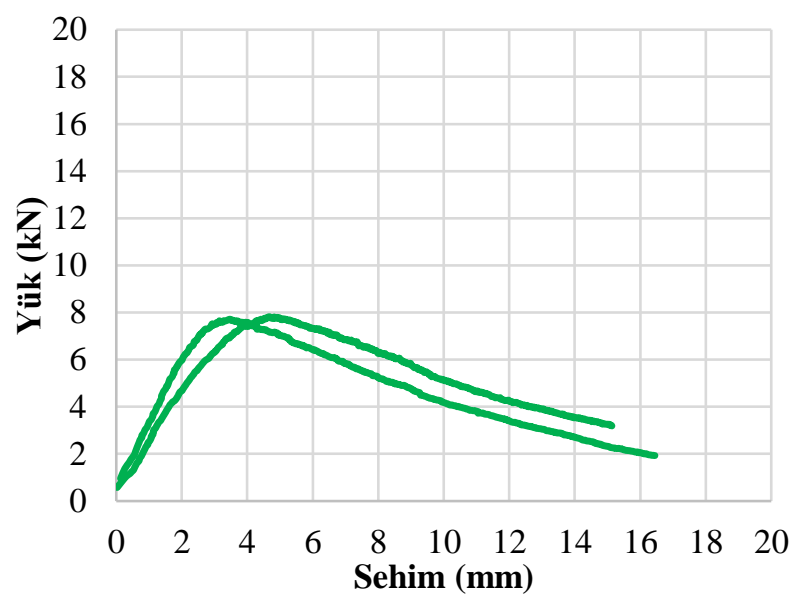

Şekil 6. Yük-sehim grafikleri $\left(+200 \mathrm{C}^{0}\right)$

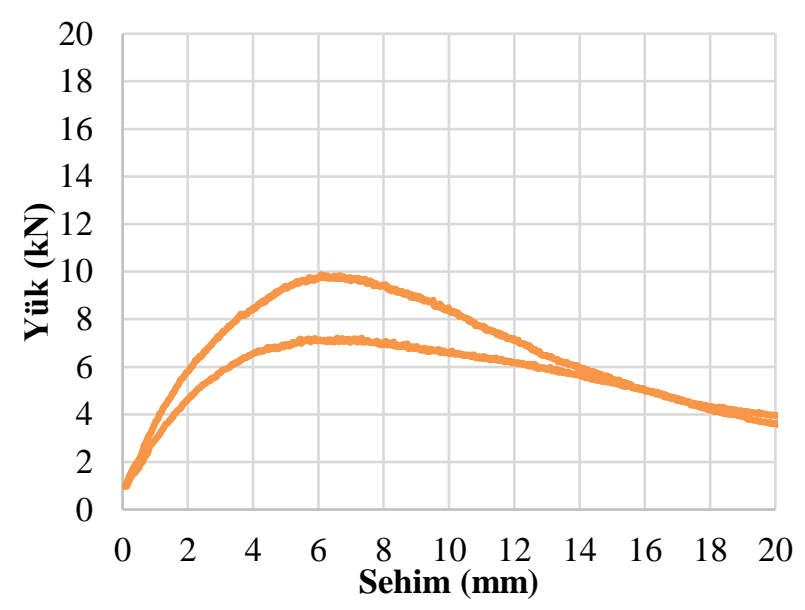

Şekil 7. Yük-sehim grafikleri $\left(+300 \mathrm{C}^{0}\right)$

Farklı 1sılardaki eğilme davranışını değerlendirmek amacıyla her 1sı türünü temsil eden grafikler tek grafik üzerinde karşılaştırılarak Şekil 8'de görülmektedir. Eğilme grafikleri incelendiğinde yüksek 1sılarda malzemede sünekliğin arttığı bununla birlikte daha fazla sehim göstererek rijitliğin düştüğü tespit edilmiştir. Düşük 1sılarda artan dayanımla birlikte rijitliğin de paralel bir davranış sergilediği görülmektedir. Ortalama eğilme dayanımları ve tokluk değerleri belirlenen kiriş numunelerin sıcaklık etkisiyle ortaya çıkan değişimler grafik olarak Şekil 9 ve Şekil 10'da verilmiştir. Eğilme testleri sonucunda bazı kiriş numunelerin kırılma halleri Şekil 11'de verilmiştir. 


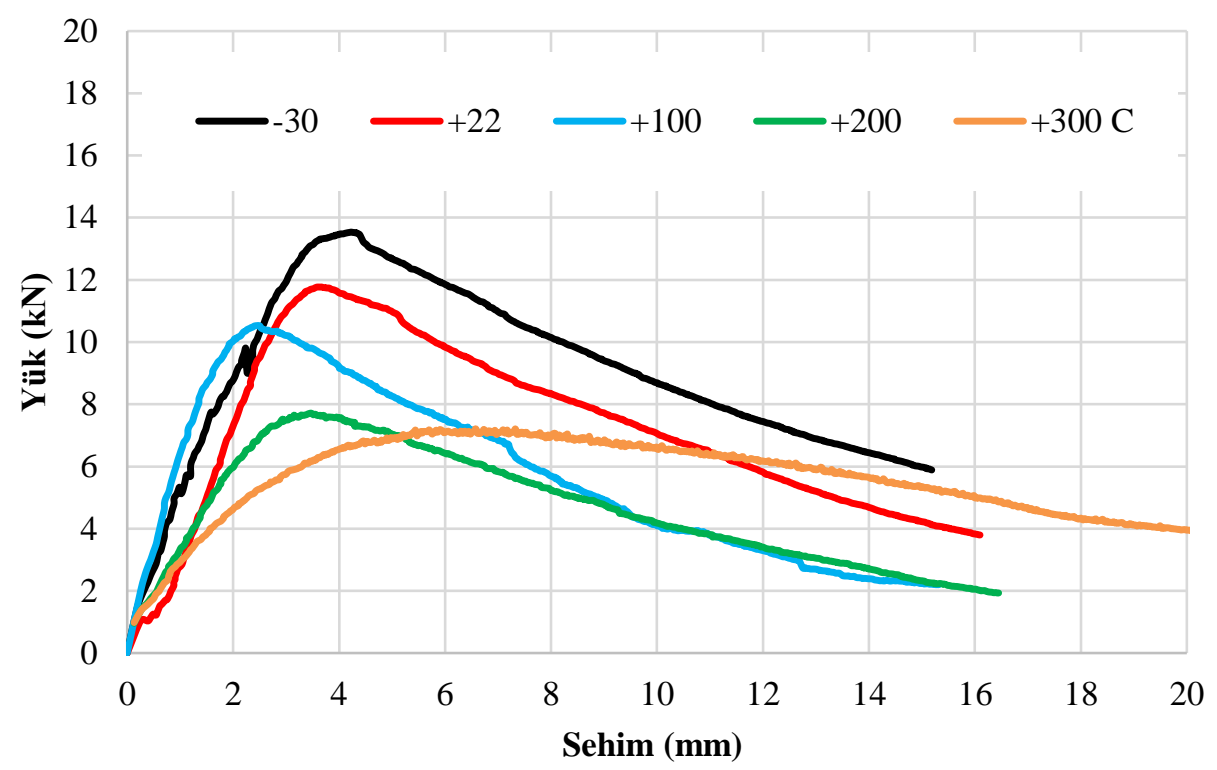

Şekil 8. Yük-sehim grafiklerinin karşılaştırması

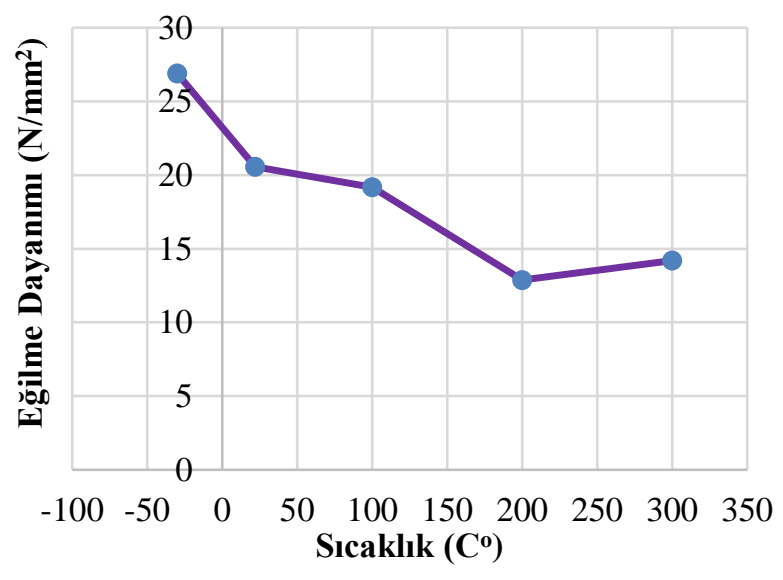

Şekil 9. Eğilme dayanımı-sıcaklık grafiği

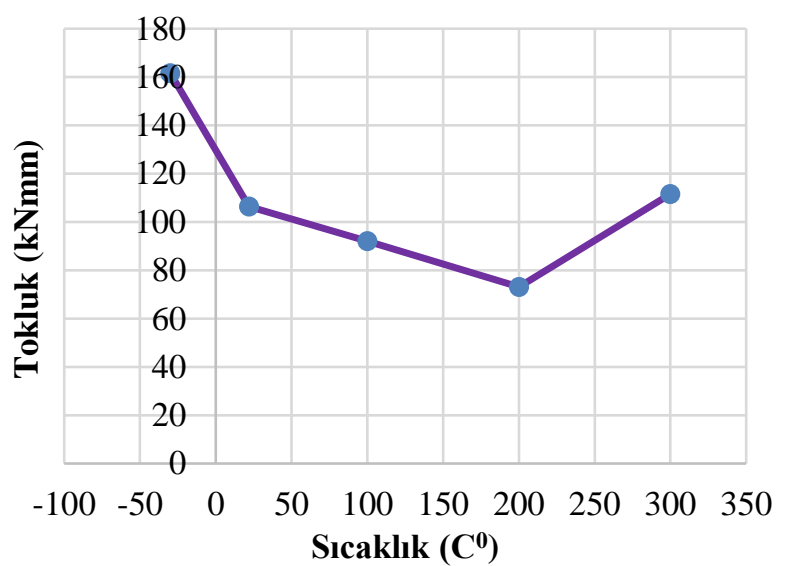

Şekil 10. Tokluk-sıcaklık grafiği

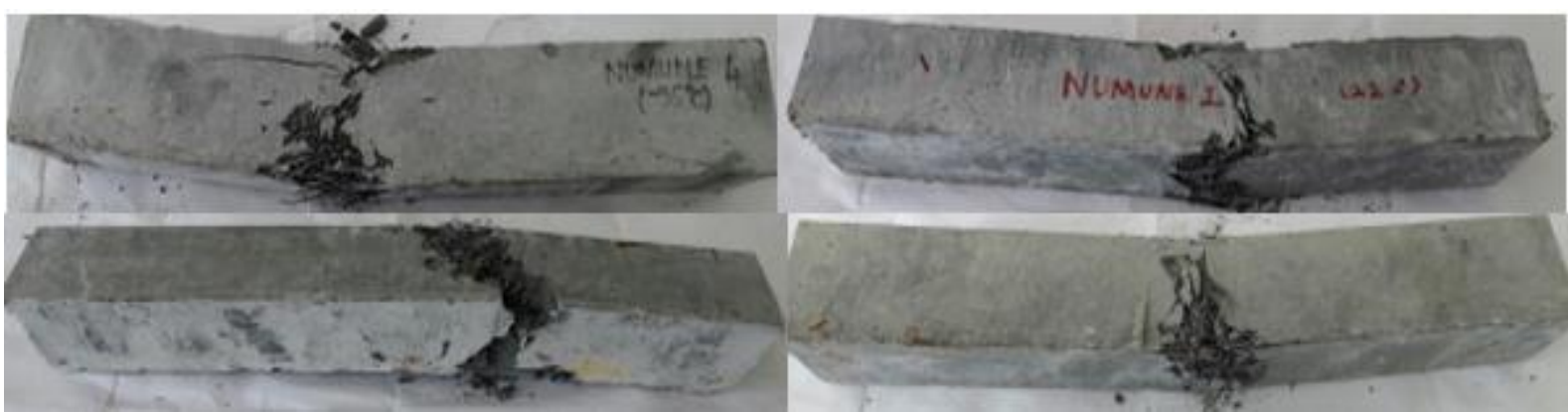

Şekil 11. Eğilme testi sonrası kırılan kiriş numuneleri

\section{Basınç Deneyi Sonuçları}


Kküp numunelere yapılan eksenel basınç deneyleri sonucunda farklı 1sılarda elde edilen basınç dayanımı Tablo 3'te verilmiştir.

Tablo 3. Basınç dayanımı değerleri

\begin{tabular}{|c|c|c|c|c|}
\hline \multirow{3}{*}{$\begin{array}{c}\text { Sicaklık }\left(C^{0}\right) \\
-35\end{array}$} & \multicolumn{4}{|c|}{ Basınç Dayanımı (N/mm²) } \\
\hline & 1 & 53,10 & Ortalama & 51,5 \\
\hline & 2 & 49,80 & & \\
\hline \multirow{2}{*}{+22} & 1 & 52,70 & \multirow{2}{*}{ Ortalama } & \multirow{2}{*}{54,4} \\
\hline & 2 & 56,01 & & \\
\hline \multirow{2}{*}{+100} & 1 & 44,51 & \multirow{2}{*}{ Ortalama } & \multirow[t]{2}{*}{45,6} \\
\hline & 2 & 46,68 & & \\
\hline \multirow{2}{*}{+200} & 1 & 43,68 & \multirow[t]{2}{*}{ Ortalama } & \multirow[t]{2}{*}{45,3} \\
\hline & 2 & 46,96 & & \\
\hline \multirow{2}{*}{+300} & 1 & 57,59 & \multirow{2}{*}{ Ortalama } & \multirow{2}{*}{55,3} \\
\hline & 2 & 52,91 & & \\
\hline
\end{tabular}

Basınç testlerinde en yüksek basınç dayanım oda sıcaklığında $54,4 \mathrm{~N} / \mathrm{mm}^{2}$ ve $+300 \mathrm{C}^{\text {o }}$ de 55,3 $\mathrm{N} / \mathrm{mm}^{2}$, en düşük basınç dayanımı $+200 \mathrm{C}^{\mathrm{o}}$ de $45,3 \mathrm{~N} / \mathrm{mm}^{2}$ dir. Isı farklarına göre basınç dayanımındaki değişim eğilme dayanımına göre daha düşük oranlarda gerçekleşmiştir. Oda sıcaklığına göre $-30 \mathrm{C}^{0}$ 'de basınç dayanımı yaklaşı \% $\%$ oranında, yüksek 1sılarda +100 ve +200 $\mathrm{C}^{\mathrm{o}}$ 'de yaklaşık \%16 oranında azalmaktadır. Küp numunelerinin farklı ısılardaki basınç dayanım değişimi Şekil 12'de verilmiştir. Basınç deneyleri sonrasında farklı 1sılardaki küp numunelerin kırılma halleri Şekil 13'de görülmektedir.

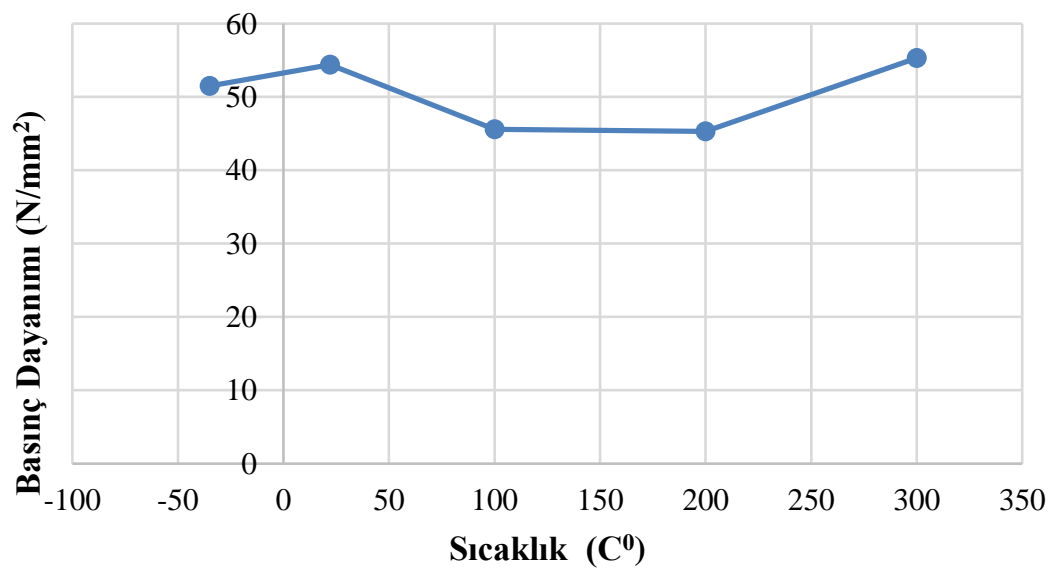

Şekil 12. Basınç dayanımı-sıcaklık grafiği 


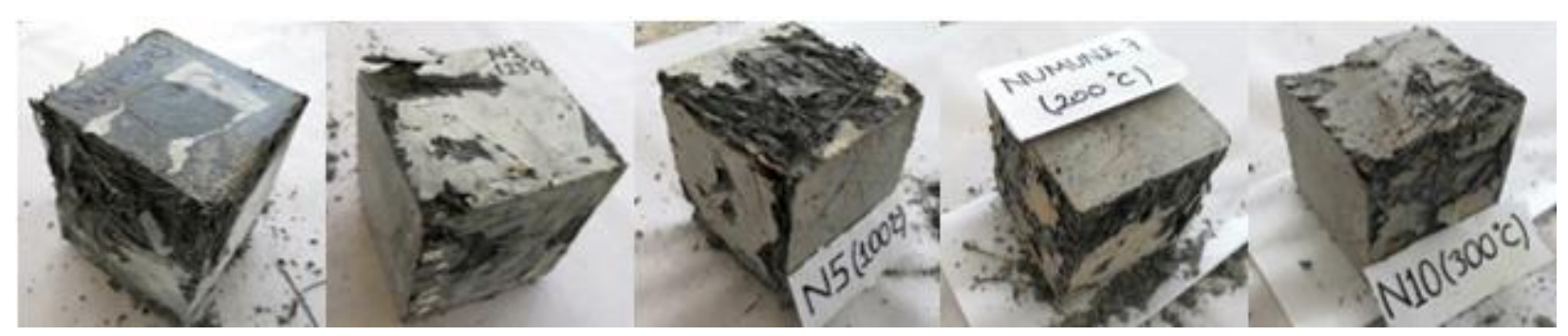

Şekil 10. Basınç numunelerinin kırılma halleri

\section{Sonuç ve Öneriler}

Deneysel çalışmalar neticesinde elde edilen sonuçlar aşağıdaki şekilde özetlenmiştir:

- SIFCON betonda en yüksek eğilme dayanımından en düşüğüne kadar belirlenen sicaklıkların siralaması $-30 \mathrm{C}^{\mathrm{o}},+22 \mathrm{C}^{\mathrm{o}},+100 \mathrm{C}^{\mathrm{o}},+300 \mathrm{C}^{\mathrm{o}},+200 \mathrm{C}^{\mathrm{o}}$ olmak üzere eğilme dayanımları sirasıly $26,89 \mathrm{~N} / \mathrm{mm}^{2}, 20,55 \mathrm{~N} / \mathrm{mm}^{2}, 19,16 \mathrm{~N} / \mathrm{mm}^{2}, 14,02 \mathrm{~N} / \mathrm{mm}^{2}, 12,88$ $\mathrm{N} / \mathrm{mm}^{2}$ dir.

- Oda sıcaklığına göre $-30 \mathrm{C}^{0}$ de yaklaşık eğilme dayanımı $\% 30$ oranında arttı̆̆ı,+300 $\mathrm{C}^{\circ}$ de $\% 32,+200 \mathrm{C}^{\circ}$ de $\% 37$ ve $+100 \quad \mathrm{C}^{\circ}$ de $\% 7$ oranında dayanımın düştüğü belirlenmiştir.

- En yüksek tokluk değeri $-30 \mathrm{C}^{0}$ 'de $161,6 \mathrm{kNmm}$, en düşük $+200 \mathrm{C}^{0}$ 'de $73,1 \mathrm{kNmm}$ ve oda sıcaklığında tokluk 106,3 kNmm bulunmuştur.

- Oda sıcaklığına göre tokluk değerlerine göre $-30 \mathrm{C}^{0}$ de $\% 52$ oranında, $+300 \mathrm{C}^{0} \% \mathrm{de}$ yaklaşık $\% 5$ oranında arttığı belirlenmiştir. +100 ve $+200 \mathrm{C}^{0}$ de sırasıyla tokluğun $\% 13$ ve $\% 31$ oranında düştüğü tespit edilmiştir.

- En yüksek basınç dayanımı oda sıcaklığında $54,4 \mathrm{~N} / \mathrm{mm}^{2}$ ve $+300 \mathrm{C}^{0}$ de $55,3 \mathrm{~N} / \mathrm{mm}^{2}$, en düşük basınç dayanımı $+200 \mathrm{C}^{0}$ 'de $45,3 \mathrm{~N} / \mathrm{mm}^{2}$ 'dir.

- Oda sıcaklığına göre basınç dayanımı $-30 \mathrm{C}^{0}$ 'de yaklaşık $\% 5$, yüksek ısılarda +100 ve $+200 \mathrm{C}^{\mathrm{o}}$ de $\% 16$ oranında azalmaktadır.

- Klasik betonlarda olduğu gibi $+200 \mathrm{ve}+300 \mathrm{C}^{0}$ gibi yüksek sıcaklıklarda dayanım artışları SIFCON betonda da görülmüştür. Ayrıca klasik betonlardan farklı olarak düşük eğilme ve tokluk değerleri SIFCON betonda yüksek değerlerdedir. Klasik betonlarda basinç dayanımına göre eğilme dayanımları \%20’ler civarında iken SIFCON ‘da yüksek sıcaklık etkisinde dahi eğilme dayanımları basınç dayanımlarının $\% 26$ ve $\% 40$ arasında değişmektedir.

\section{Kaynaklar}

[1] Baradan, B. Yazıc1, H. Ün, H. Beton ve Betonarme Yapılarda Kalıc1lı (Durabilite), THBB yayınlar1, 2010, pp. 70-74.

[2] Aydın, S. Yazıcı, H. Baradan, B. High Temperature Resistance of Normal Strength and Autoclaved High Strength Mortars Incorporated Polypropylene and Steel Fibers. Construction and Building Materials. 2008; 22, pp. 504-512. 
[3] Shannag, M.J. Barakat, S., Jaber, F. Structural Repair of Shear Deficient Reinforced Concrete Beams Using SIFCON, Magazine of Concrete Research, 2001; 53,6, 391-403

[4] Bayramov, F. , İlki, A., Taşdemir, C. Taşdemir, M. A., Yerlikaya, M.. SFRCs for Concrete Roads in Heavily Trafficked Situations, 9th International Symposium on Concrete Roads, 2, İstanbul, Turkey, 2004; April 4-7, 73-82.

[5] Naaman, A.E. Proceedings of the International Workshop, SIFCON: Tailored Properties for Structural Performance. Edited by H. W. Reinhart and A.E. Naaman. RILEM. Published by E \& FN Spon, 1991, London.

[6] Rajai Z. Al-Rousana, Mohammad J. Shannagb Shear Repairing and Strengthening of Reinforced Concrete Beams Using SIFCON Structures. 2018;14 389-399.

[7] Sengul O. Mechanical properties of slurry infiltrated fiber concrete produced with waste steel fibers Construction and Building Materials. 2018; 186 1082-1091

[8] Elavarasi D., Saravana Raja Mohan K. On low-velocity impact response of SIFCON slabs under drop hammer impact loading Construction and Building Materials. 2018;160 127-135.

[9] Ipek M., Aksu M., Uysal M., Yilmaz K. Vural I. Effect of pre-setting pressure applied flexure strength and fracture toughness of new SIFCON + RPC composite during setting phase Construction and Building Materials. 2015;79 90-96

[10] Abdollahi B., Bakhshi M., Mirzaee Z., Shekarchi M., Motavalli M. SIFCON strengthening of concrete cylinders in comparison with conventional GFRP confinement method Construction and Building Materials. 2012;36 765-778.

[11] Tuyan M., Yazic1 H. Pull-out behavior of single steel fiber from SIFCON matrix Construction and Building Materials. 2012;35 571-577.

[12] Farnam Y., Moosavi M., Shekarchi M., Babanajad S.K., Bagherzadeh A. Behaviour of Slurry Infiltrated Fibre Concrete (SIFCON) under triaxial compression Cement and Concrete Research. 2010;40 1571-1581.

[13] Beglarigale A., Yalçınkaya Ç., Yigiter H., Yazıcı H.. Flexural performance of SIFCON composites subjected to high temperature. Construction and Building Materials. 2016; 104, 99-108. 